\title{
Assessing Respiratory Function Depends on Mechanical Characteristics of Balloon Catheters
}

\author{
Stephan Walterspacher MD, Lilli Isaak, Josef Guttmann PhD, Hans-Joachim Kabitz MD, \\ and Stefan Schumann PhD
}

\begin{abstract}
BACKGROUND: Respiratory muscle function and lung and chest wall mechanics are reliably assessed by esophageal and gastric balloon catheters. The aim of this in vitro bench study was to assess the mechanical properties of commercially available balloon catheters using an experimental model with 3 defined compliances $\left(27,54,90 \mathrm{~mL} / \mathrm{cm} \mathrm{H}_{2} \mathrm{O}\right)$. METHODS: Six catheters were investigated in 4 conditions: (1) balloon pressure during initial inflation, (2) static pressure measurements at different filling volumes, (3) estimation of set compliances in the experimental lung model at different levels of superimposed pressure, and (4) elastic balloon properties after $16 \mathrm{~h}$ of inflation. RESULTS: 5/6 catheters showed initial pressure artifacts resulting from material adhesion. All static pressure measurements could be performed with an error $<1 \mathrm{~cm} \mathrm{H}_{2} \mathrm{O}$. Balloon overfilling resulted in larger errors in 4/6 catheters. Compliance determined from pressure measurements via the catheters differed by $<5 \%$ from that determined from direct pressure measurements. Sixteen hours of inflation resulted in a broader working range, that is, overfilling effects occurred at higher filling volumes. CONCLUSIONS: The reliability of pressure measurements and estimation of the lung model's compliance in the tested catheters are high. Filling volume appears to be critical for precise pressure measurement and compliance estimation. At first use, adhesion of the balloon material might prevent reliable pressure measurement. Key words: esophagus; work of breathing; artificial respiration; pulmonary mechanics; lung compliance. [Respir Care 2014;59(9):1345-1352.

(C) 2014 Daedalus Enterprises]
\end{abstract}

\section{Introduction}

Assessment of esophageal and gastric pressures is a longstanding and valuable tool in examining the pathophysiology of the respiratory system dating back to Luciani in $1878 .{ }^{1}$ To date, esophageal (and gastric) pressure measurement is considered the accepted standard in the discrimination of respiratory effort-related arousals during sleep. It is indispensable in measuring lung and chest wall compliance, work of breathing, respiratory muscle

Drs Walterspacher and Kabitz are affiliated with the Department of Pneumology, University Hospital of Freiburg, Freiburg, Germany. Ms Isaak and Drs Guttmann and Schumann are affiliated with the Department of Anesthesiology, Division for Experimental Anesthesiology, University Medical Center Freiburg, Freiburg, Germany.

The authors have disclosed no conflicts of interest.

Supplementary material related to this paper is available at http:// www.rcjournal.com. function (ie, transdiaphragmatic pressures) and is valuable for the assessment of trigger function as well as patientventilator synchrony in mechanically ventilated patients. ${ }^{2-10}$ Esophageal (and gastric) pressure measurement also assists in treatment stratification in ARDS ${ }^{11,12}$ and is currently included in mechanical ventilation systems (eg, Avea, CareFusion, San Diego, California).

\footnotetext{
Dr Walterspacher presented a version of this paper at the ERS Annual Congress 2013, held September 7-11, 2013, in Barcelona, Spain. Dr Schumann presented a version of this paper at the German Congress of Anesthesiology and Intensive Care 2013, held April 20-22, 2013 in Nürnburg, Germany, and at the 33rd International Symposium on Intensive Care and Emergency Medicine, held March 19-22, 2013, in Brussels, Belgium.

Correspondence: Stephan Walterspacher MD, Department of Pneumology, University Hospital of Freiburg, Killianstrasse 5, 79106 Freiburg, Germany. E-mail: stephan.walterspacher@klinikum-konstanz.de.
}

DOI: $10.4187 /$ respcare. 02974 


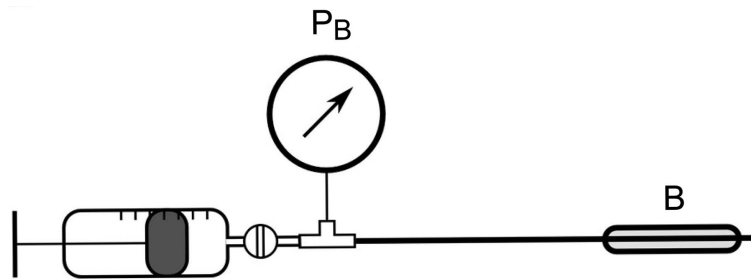

Fig. 1. Schematic setup for experiment I: direct pressure measurement $\left(P_{B}\right)$ of the balloon $(B)$ at various filling volumes. During the measurements, the syringe was disconnected from the balloon site via a valve to prevent volume reflux.

In addition to careful balloon placement, design, geometry, and filling volumes of the balloons have a major impact on the characteristics of pressure transduction thus affecting measurement quality. ${ }^{1,13-17}$ When measuring at extreme lung volumes such as residual volume or total lung capacity, this point is even more important, ${ }^{18}$ and filling volumes have to be adapted. ${ }^{17}$

For these reasons, detailed knowledge about the mechanical characteristics of the balloon catheters used is crucial. ${ }^{17}$ To date, the balloons' pressure-volume (P-V) characteristics of most commercially available balloon catheters have not been investigated, and information provided by the manufacturers of commercial catheters is scarce. Therefore, in this study, we aimed to assess the mechanical properties and validity of pressure measurements of 6 commercially available balloon catheter systems in a laboratory setting using an experimental lung model.

\section{Methods}

Six different types of invasive pressure measurement balloon catheters were investigated (for details, see the supplementary materials at http://www.rcjournal.com). Three of the tested catheters were equipped with one balloon for pressure assessment (CooperSurgical, Leisegang Feinmechanik GmbH, Berlin, Germany; and 16/8 Fr adult SmartCath, Viasys Healthcare, Palm Springs, California). The 3 other catheters (Bösch, Bösch GmbH, Gottenheim, Germany; nSpire, ZAN, Oberthulba, Germany; and NutriVent, Sidam, San Giacomo, Italy) were equipped with a second separate balloon for measuring transdiaphragmatic pressure difference (double-balloon catheter). These balloons were handled separately, that is, each of the following measurements was performed for each single balloon. The mechanical balloon characteristics were compared in 4 experimental setups as indicated below.

\section{Technical Measurements}

All pressure measurements were performed using piezoresistive pressure sensors (SI-Special Instruments

\section{QUICK LOOK}

\section{Current knowledge}

The measurement of esophageal and gastric pressures to determine lung and chest wall mechanics as well as work of breathing is well described. The ideal characteristics of balloon catheters for these measurements and the impact of use over time are not as well defined.

\section{What this paper contributes to our knowledge}

Pressure-volume characteristics and appropriate filling volumes varied widely among different balloon catheters and were critical for accurate pressure measurements. Inflating and deflating the balloon before insertion prevented artifacts due to material adhesion. Filling of balloon catheters to the appropriate volume is required to maintain measurement accuracy.

GmbH, Nördlingen, Germany) with maximal ranges of \pm 20 or $\pm 100 \mathrm{~cm} \mathrm{H}_{2} \mathrm{O}$. Ventilation flows were measured using a Fleisch pneumotachograph (Type 2, Dr Fenyves und Gut Deutschland GmbH, Hechingen, Germany), and volume was calculated by numerical integration of the flow. Data were recorded using a costumer-adapted software package based on Labview (Labview 7.1, National Instruments, Austin, Texas) at a sample frequency of $200 \mathrm{~Hz}$. Offline analysis was performed using MatLab R2012a (MathWorks, Natick, Massachusetts).

\section{Experimental Setup}

P-V Curves (Experiment I). To determine the P-V curves of the balloon catheters, we measured the balloon pressure during slow continuous inflation (PS01-23S $\times 80$ computer-controlled injection pump and series E1100 controller, LinMot, Spreitenbach, Switzerland) at a rate of 0.16 or $0.24 \mathrm{~mL} / \mathrm{s}$ and during stepwise inflation realizing volume steps of 0.2 or $0.3 \mathrm{~mL}$, both depending on the balloon's maximal filling volume estimated from its geometry (Fig. 1). The P-V was continuously recorded when inflation was performed immediately after unpacking the catheters to focus on their characteristics during the very first inflation. The slow inflation measurement consisted of 6 inflation and deflation cycles in which, depending on the balloon's size, 4 or $6 \mathrm{~mL}$ of air were insufflated continuously (see the supplementary materials at http://www.rcjournal.com) within a fixed time of $25 \mathrm{~s}$ and subsequently extracted (dynamic model). To allow for comparison of dynamic versus static inflation, the inflation behavior was investigated by applying and drawing the same total volumes in 15 steps of 0.2 or $0.3 \mathrm{~mL}$ of air (static model). 


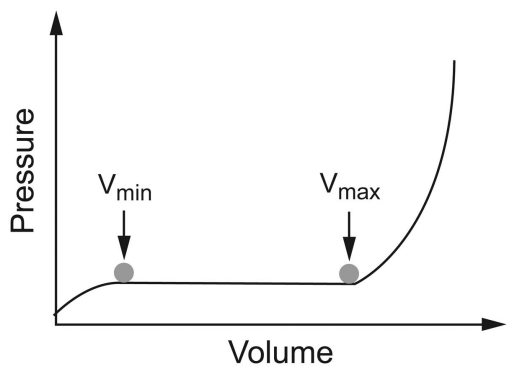

Fig. 2. Schematic of a typical catheter balloon's pressure-volume relationship. $V_{\min }$ and $V_{\max }$ indicate the lower limit and upper limit and maximum of the filling volume range within which the pressure inside the balloon is constant, independent of the filling volume.

The suggested optimal filling ranges of the balloons were determined by detailed inspection of the horizontal segment (ie, working range) of the P-V curves (Fig. 2), as suggested previously. ${ }^{1,14}$ The recommended lower-limit filling volume $\left(\mathrm{V}_{\min }\right)$ of a balloon was determined as the volume marking the beginning of the horizontal $\mathrm{P}-\mathrm{V}$ curve segment. The recommended upper-limit filling volume $\left(\mathrm{V}_{\text {max }}\right)$ was determined as the volume marking the end of the horizontal P-V curve segment.

Reliability of Pressure Measurements Under Static Conditions (Experiment II). To investigate the reliability of pressure measurements during static conditions, the balloons were placed inside an air-tight chamber pressurized with $0,4,8,12$, and $16 \mathrm{~cm} \mathrm{H}_{2} \mathrm{O}$, as controlled by direct pressure measurement $\left(\mathrm{P}_{\mathrm{D}}\right)$ (Fig. 3). Before the measurements, all air was removed from the catheter by a syringe, and the syringe was then disconnected to allow the balloon to unfold to its unfilled position to avoid negative pressures. Each balloon was tested in 4 filling conditions. (1) In the empty condition, no additional volume was applied. (2) In the mid-working range, the balloon was inflated to half of the recommended $\mathrm{V}_{\max }$ as identified in the preceding experiment (see above). (3) At the recommended $\mathrm{V}_{\max }$, the balloon was inflated to $\mathrm{V}_{\text {max }}$ as identified in the preceding experiment (see above). (4) In the overinflation condition, the balloon was inflated to 2 -fold of the $\mathrm{V}_{\max }$ as identified in the preceding experiment. Each measurement was repeated 5 times.

\section{Reliability of Compliance Measurements (Experiment} III). To analyze the dynamic behavior of the catheter balloons, we investigated the reliability of determination of respiratory system compliance via catheter measurement in an experimental lung model (Fig. 4). Respiratory system compliances were imitated using glass bottles filled with copper wool to ensure isothermal conditions. ${ }^{19}$ Two bottles (54 and $27 \mathrm{~L}$ ) were used separately and connected in parallel to reflect 3 different compliances. The model was ventilated in volume controlled

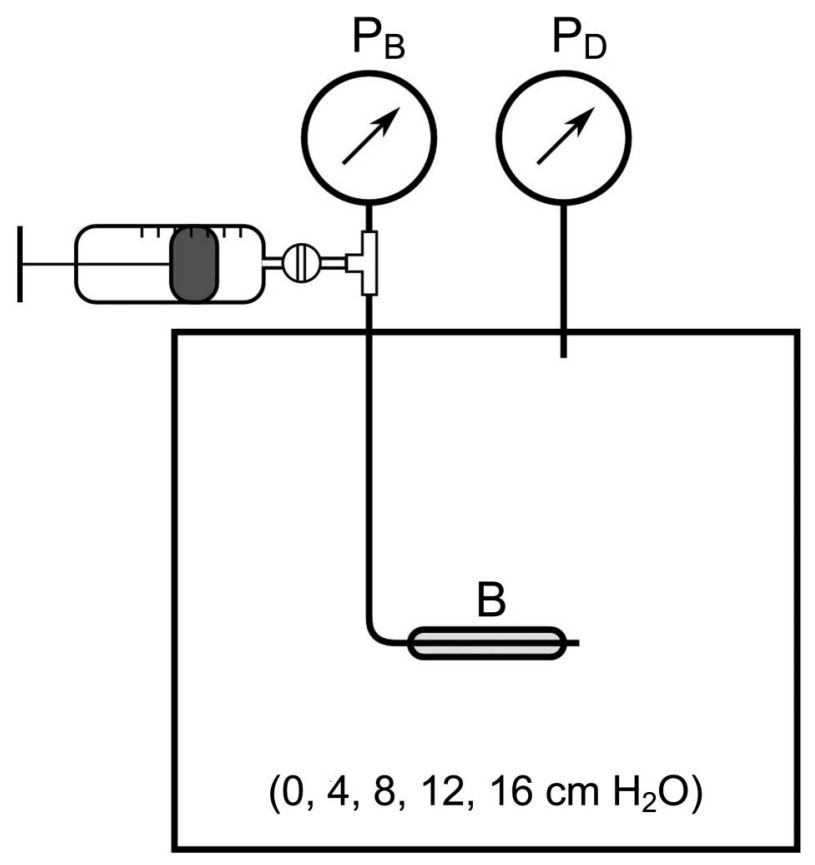

Fig. 3. Schematic of the pressure measurement setup for experiment II. The balloon (B) was placed in an air-tight chamber, the filling conditions were applied via a syringe, and the ambient pressures $\left(P_{D}\right)$ were applied. During the measurements, the syringe was disconnected from the balloon site via a valve to prevent volume reflux. The balloon pressure $\left(P_{B}\right)$ was directly measured for each experimental condition.

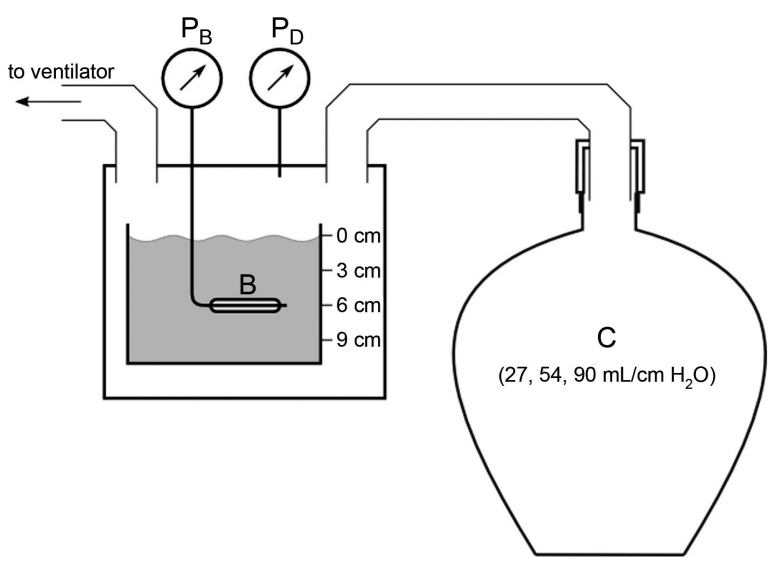

Fig. 4. Schematic of the compliance measurement setup. The simulated compliance (C) was determined by one of 2 copper woolfilled rigid glass bottles or a combination of both. In a pressure measurement chamber connected to the compliance model, the pressure was measured directly $\left(P_{D}\right)$ or via the balloon catheter $\left(P_{B}\right)$ under test, placed in a water basin for simulating superimposed pressure of $0-9 \mathrm{~cm} \mathrm{H}_{2} \mathrm{O}$. The lung model was ventilated by a ventilator, and compliance was calculated from the pressurevolume relationship. $\mathrm{B}=$ balloon.

mode using a commercially available intensive care ventilator (Evita 4, Dräger, Lübeck, Germany). Tidal volume 
was set to $500 \mathrm{~mL}$, and breathing frequency was set at 15 breaths/min.

To simulate additional hydrostatic pressure, the balloons were placed in a water basin at various water depths, reflecting superimposed pressures of $0,3,6$, and $9 \mathrm{~cm} \mathrm{H}_{2} \mathrm{O}$. Each catheter was filled to a volume corresponding to the mean of the respective $\mathrm{V}_{\min }$ and $\mathrm{V}_{\max }$.

Compliance of the mechanically ventilated experimental model was determined from the P-V relationship resulting from: (1) $\mathrm{P}_{\mathrm{D}}$, (2) pressure measurement via the respective balloon $\left(\mathrm{P}_{\mathrm{B}}\right)$, and (3) compliance calculated from the ventilator based on expiratory tidal volume divided by the difference between end-inspiratory and end-expiratory airway pressure (expiratory $\mathrm{V}_{\mathrm{T}} /$ [end-inspiratory $\mathrm{P}_{\mathrm{aw}}-$ end-expiratory $\left.\mathrm{P}_{\mathrm{aw}}\right]$ ). This compliance model is proposed to reflect the physiological dynamics of a mechanically ventilated human respiratory system. Of note, the determination of compliance is influenced by the shape of the catheter's (nonlinear) P-V curve.

Long-Term Usage Characteristics (Experiment IV). To investigate the long-term characteristics of the balloons after intensive usage, the measurements of experiment I were repeated after experiment III after all catheters had been inflated to 2-fold of their individual $\mathrm{V}_{\max }$ and left unchanged for $16 \mathrm{~h}$. Using this overinflation, we simulated a continuous mechanical load of the balloons during long-term measurements in situ. Overinflation was also applied to test the tensile strength and to magnify the possible changes in the balloons' compliance due to longterm usage.

\section{Statistics}

The pressure and volume measurement precision of a typical mechanical ventilator is given with $\pm 2 \mathrm{~cm} \mathrm{H}_{2} \mathrm{O}$, with $\pm 10 \%$ of the measured value (manual for the Evita 4). Therefore, absolute deviations in pressure measurement of $>1 \mathrm{~cm} \mathrm{H}_{2} \mathrm{O}$ and in compliance determination of $>10 \%$ were defined before the event as relevant. ${ }^{14}$ Unless stated otherwise, values are normally distributed and given as mean $\pm \mathrm{SD}$. Comparisons between pressure and compliance estimation via catheter and $\mathrm{P}_{\mathrm{D}}$ values were analyzed using the Student paired $t$ test. The influence of factors (balloon type, method of determination, and superimposed pressure) on compliance estimation was analyzed using multifactorial analysis of variance, applying the Fisher protected least-significant difference test. Statistical significance was defined as $P<.05$. Statistical results were calculated using StatView 5.0 (SAS Institute, Cary, North Carolina).
Table 1. Balloon Catheter Filling Volumes

\begin{tabular}{lccc}
\hline \hline \multicolumn{1}{c}{ Balloon Position } & $\begin{array}{c}\mathrm{V}_{\min } \\
(\mathrm{mL})\end{array}$ & $\begin{array}{c}\mathrm{V}_{\max } \\
(\mathrm{mL})\end{array}$ & $\begin{array}{c}\mathrm{V}_{\max / 16 \mathrm{~h}} \\
(\mathrm{~mL})\end{array}$ \\
\hline $\begin{array}{l}\text { Bösch catheter } \\
\quad \text { Proximal }\end{array}$ & 0.4 & 1 & 2 \\
$\quad \begin{array}{l}\text { Distal } \\
\text { CooperSurgical catheter (single) }\end{array}$ & 0.4 & 1 & 2 \\
$\quad$ nSpire catheter & 0.2 & 1.2 & 2 \\
$\quad$ Proximal & 0.2 & 0.8 & 1.6 \\
$\quad$ Distal & 0.2 & 0.8 & 1.6 \\
SmartCath catheter (single) & & & \\
$\quad$ 16 Fr & 0.5 & 2.4 & 3 \\
$\quad$ 8 Fr & 0.3 & 1.5 & 3 \\
NutriVent catheter & & & \\
$\quad$ Proximal & 0.5 & 3 & 4.5 \\
$\quad$ Distal & 0.5 & 2.5 & 5
\end{tabular}

Values represent minimal $\left(\mathrm{V}_{\min }\right)$ and maximal $\left(\mathrm{V}_{\max }\right)$ filling volumes for catheters as identified from the pressure relationships during inflation (experiment I) and shifted maximal filling volume $\left(\mathrm{V}_{\max / 16 \mathrm{~h}}\right)$ following $16 \mathrm{~h}$ of inflation (experiment IV).

\section{Results}

The detailed characteristics and P-V curves for all tested balloons according to the experimental setup are available online (see the supplementary materials at http:// www.rcjournal.com).

\section{Initial P-V Relationships (Experiment I)}

All catheters presented distinct P-V relationships. All catheters except the nSpire showed a clear deviation of the first inflation profile (see supplementary materials at http://www.rcjournal.com) with respect to the following measurements. In 4 catheters, deviations ceased with the second inflation (NutriVent, CooperSurgical, and both SmartCath catheters). Initial pressure deviation was most prominent for both balloons of the Bösch double-lumen catheter, which showed rapid pressure increases to values above the sensor's pressure range during the first inflation and large nearly constant pressure transmission for a wide volume range for the following inflations. All catheters except the nSpire showed a distinct volume range with constant pressure transmission. In contrast, the nSpire catheter featured a nonlinear behavior throughout the measured volume range; $\mathrm{V}_{\min }$ and $\mathrm{V}_{\max }$ as presented in Table 1 are suggested according to the range with the least $\mathrm{P}-\mathrm{V}$-related change.

The P-V relationships during stepwise inflation were similar to those measured during continuous inflation (see supplementary materials at http://www.rcjournal.com). Table 1 lists $\mathrm{V}_{\min }$ and $\mathrm{V}_{\max }$ as identified from the $\mathrm{P}-\mathrm{V}$ curves for each investigated balloon catheter. 


\section{Assessing Respiratory Function Depends on Balloon Catheter Characteristics}

\section{Reliability of Static Pressure Measurement (Experiment II)}

Static pressure as assessed via $\mathrm{P}_{\mathrm{D}}$ exceeded the pressure measured via the catheter in $94 \%$ of all measurements. If the filling volume was set to mid-working range volumes or $\mathrm{V}_{\max }$, the difference between directly measured pressure and catheter-measured pressure was $<0.2 \mathrm{~cm} \mathrm{H}_{2} \mathrm{O}$, except if the nSpire catheter was used. Pressure measurement via the catheter led to larger underestimations of the pressure as identified by direct measurement if the balloons were overinflated (Table 2). Corresponding mean differences were $>1 \mathrm{~cm} \mathrm{H}_{2} \mathrm{O}$ in 2 catheters (Bösch and nSpire).

\section{Determination of Compliance (Experiment III)}

By $\mathrm{P}_{\mathrm{D}}$, the compliances of the respiratory system models were determined to be $85.5 \pm 2.7,61.5 \pm 1.9$, and $29.6 \pm 1.1 \mathrm{~mL} / \mathrm{cm} \mathrm{H}_{2} \mathrm{O}$. On average, the compliance estimated by the ventilator was $2.0 \pm 1.7 \mathrm{~mL} / \mathrm{cm} \mathrm{H}_{2} \mathrm{O}$ larger $(P<.001)$ and that estimated by catheter measurement was $0.9 \pm 0.9 \mathrm{~mL} / \mathrm{cm} \mathrm{H}_{2} \mathrm{O}$ larger $(P<.001)$ than the compliance determined by $\mathrm{P}_{\mathrm{D}}$. Balloon type, method of determination, and superimposed pressure all influenced the compliance results (all $P<.002$ ). Each difference in estimated compliance between directly measured pressure and catheter-measured pressure determined with any catheter and in any situation of superimposed pressure was $<4.5 \%$. Across all measurements, the relative differences between compliance measured directly and via catheter were $0.8 \pm 0.9 \%, 1.6 \pm 0.9 \%, 2.2 \pm 1.2 \%$, and $1.4 \pm 0.9 \%$ for $0,3,6$, and $9 \mathrm{~cm} \mathrm{H}_{2} \mathrm{O}$ of superimposed pressure, respectively. Calculated compliances from all conditions are provided (see the supplementary materials at http://www.rcjournal.com).

\section{Long-Term P-V Relationships (Experiment IV)}

After $16 \mathrm{~h}$ of overinflation, 4 of 6 catheters featured a transition of $\mathrm{V}_{\max }$ to higher filling volumes compared with experiment I (see Table 1), whereas $\mathrm{V}_{\text {min }}$ remained constant in all catheters. Detailed information on all P-V curves is available (see the supplementary materials at http://www.rcjournal.com).

\section{Discussion}

The main findings of this study can be summarized as pressure recordings critically depend on balloon design ${ }^{13}$ and on filling volumes with increasing pressures along with rising balloon filling volumes. ${ }^{18}$ Because these characteristics are usually not reported by the manufacturers, it is essential for the user to reflect on these circumstances whenever using balloon catheters for pressure measurements. This study revealed that the nonlinear P-V characteristics of each balloon catheter are different and that $\mathrm{V}_{\min }$ and $\mathrm{V}_{\max }$ need to be known by the user for correct application.

Balloon material adhesion at the initial inflation after unpacking the catheter proved to be a consistent factor of incorrect pressure transduction in all catheters and was consistently eliminated by balloon inflation and deflation after the first balloon inflation. The P-V characteristics of the balloons were different according to the balloons' geometry and material characteristics; in all catheters except the $\mathrm{nSpire}$, the $\mathrm{P}-\mathrm{V}$ characteristics exhibited a nearly linear relationship within a defined volume range characterized by a horizontal course of the P-V curve. This horizontal segment of a balloon's P-V curve defines the key feature of any balloon catheter. Within the limits of the horizontal $\mathrm{P}-\mathrm{V}$ curve segment, the balloon pressure is independent of the filling volume. ${ }^{14}$ Consequently, this horizontal $\mathrm{P}-\mathrm{V}$ curve segment limited by $\mathrm{V}_{\min }$ and $\mathrm{V}_{\max }$ defines the operating range of the balloon catheter with respect to the filling volume. ${ }^{1,14}$

The results of previous experiments provide evidence that this in vitro linear relationship also corresponds to in vivo measurements. ${ }^{1,13,18}$ In particular, measurements at near total lung capacity exhibit an artificial increase in esophageal pressures with increasing balloon volume. ${ }^{15,18}$ Therefore, catheters used in the thoracic compartment should be filled with respect to $\mathrm{V}_{\text {min }}$ to retain optimal pressure transduction. ${ }^{14,17}$ Pressures in the abdominal compartment are contrary in the respiratory cycle with respect to thoracic pressures. Accordingly, gastric balloons should be inflated to $\mathrm{V}_{\max }$ to ensure optimal assessment of transdiaphragmatic pressures. ${ }^{17}$ This can also be derived from experiment II (see Table 2 and Fig. 3), in which errors in the balloons' pressure transmission remained low if filling volumes were adjusted to higher volumes.

To the best of our knowledge, this study is the first to assess the characteristics of the long-term usage of balloon catheters as occurs during sleep laboratory studies or in esophageal pressure-guided mechanical ventilation. This is of special importance because distending forces due to the balloon's filling volume might interfere with the P-V characteristics of the balloon and influence the recorded pressures for the reasons mentioned above. Following the extensive testing in experiments I-III, all catheters were kept filled at 2-fold their individual $\mathrm{V}_{\max }$ for $16 \mathrm{~h}$. Four of 6 catheters exhibited a right-shifted P-V curve, which led to an extended horizontal P-V curve segment. This finding is suggested to be of minor importance for long-term pressure measurements because this leads to an extended working range of the balloon. ${ }^{14}$ 


\section{Assessing Respiratory Function Depends on Balloon Catheter Characteristics}

Table 2. Differences Between Set Pressure and Pressure Measured via Balloon Catheters

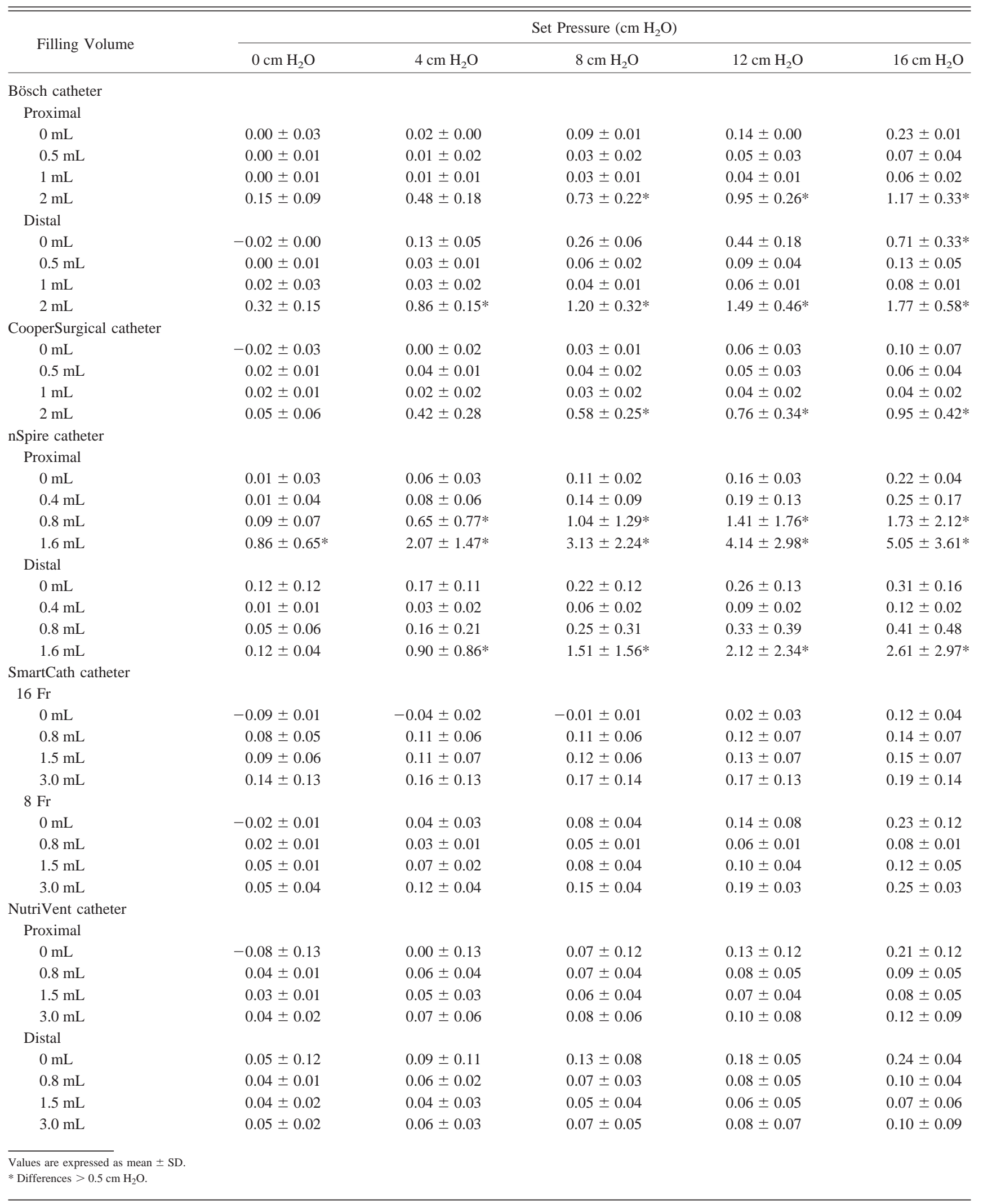


The balloon's filling volume, the method of determination, and superimposed pressure all had an impact on the determined compliance value of the experimental lung model. Of note, the resulting measurement errors in determined compliance were well below the a priori-defined cutoff values. Compliance values, as assessed by the balloon catheter measurements, proved to more closely reflect the compliance of the lung model used compared with a state-of-the-art intensive care mechanical ventilator. These findings were consistent for all compliance models and catheters used, making them a reliable tool for physiological studies and therapy guidance.

In a clinical perspective, incorrect filling volumes of balloons may lead to incorrect pressure transduction, especially in patients with ARDS and high PEEP (as shown in Experiment II, Table 2). In esophageal pressure-guided mechanical ventilation, PEEP is adjusted to avert alveoli collapse or pulmonary overdistention and maintain transpulmonary pressures of $0-10 \mathrm{~cm} \mathrm{H}_{2} \mathrm{O} .{ }^{11}$ Therefore, errors of $>1 \mathrm{~cm} \mathrm{H}_{2} \mathrm{O}$ may lead to deleterious decisions with false adjustments of PEEP levels. These errors may lead to a wrong interpretation as depicted in a false loss of compliance in physiological studies. ${ }^{14}$

\section{Critique of Methods}

All experiments were performed with only one catheter for each manufacturer; therefore, consistency of manufacturing and processing might not have been adequately addressed. However, the randomly picked scenario reflects real-life conditions in which the user has to rely on a stable manufacturing process and cannot compare several catheters from different production lines within one manufacturer before usage.

Previous studies have addressed the pressure signal transmission of commercially available esophageal balloon catheters, showing that catheters vary greatly in signal transmission. ${ }^{8}$ Signal transmission does not solely rely on the balloons' resistance, but also on the volume displacement coefficients according to the volume of air in the balloon, tubing, and pressure transducers. ${ }^{20}$ This issue has not been addressed in this study due to its high variability with regard to the tubing systems and pressure transducers used with respect to the previous studies. ${ }^{14,20}$

In this study, we exclusively performed in vitro assessment of balloon catheter characteristics. We cannot exclude with certainty that in vivo measurements would have revealed different results. However, the current approach was chosen to minimize nonmaterial-related variability and to keep the environmental factors as stable as possible to most accurately assess the mere material characteristics rather than pressure transmission related to individual patient/subject characteristics.

\section{Conclusions}

Pressure measurements, compliance estimation, and long-term characteristics were assessed in 6 commercially available balloon catheter systems. However, to prevent artifacts caused by material adhesion, the balloons should be inflated and deflated before placement. P-V characteristics and appropriate filling volumes vary greatly among different balloon catheters and are crucial for pressure measurement. Users should be well aware of the accurate filling volume of the corresponding balloon catheter system applied.

\section{REFERENCES}

1. Mead J, Mcllroy MB, Selverstone NJ, Kriete BC. Measurement of intraesophageal pressure. J Appl Physiol 1955;7(5):491-495.

2. Berry RB, Budhiraja R, Gottlieb DJ, Gozal D, Iber C, Kapur VK, et al. Rules for scoring respiratory events in sleep: update of the 2007 AASM Manual for the Scoring of Sleep and Associated Events. J Clin Sleep Med 2012;8(5):597-619.

3. Passam F, Hoing S, Prinianakis G, Siafakas N, Milic-Emili J, Georgopoulos D. Effect of different levels of pressure support and proportional assist ventilation on breathing pattern, work of breathing and gas exchange in mechanically ventilated hypercapnic COPD patients with acute respiratory failure. Respiration 2003;70(4): 355-361.

4. Thille AW, Cabello B, Galia F, Lyazidi A, Brochard L. Reduction of patient-ventilator asynchrony by reducing tidal volume during pressure-support ventilation. Intensive Care Med 2008;34(8):1477-1486.

5. Rajacich N, Burchard KW, Hasan F, Singh A. Esophageal pressure monitoring: a practical adjuvant to hemodynamic monitoring with positive end-expiratory pressure. Heart Lung 1988;17(5):483-488.

6. Kabitz HJ, Sonntag F, Walker D, Schwoerer A, Walterspacher S, Kaufmann S, et al. Diabetic polyneuropathy is associated with respiratory muscle impairment in type 2 diabetes. Diabetologia 2008; 51(1):191-197.

7. Walterspacher S, Scholz T, Tetzlaff K, Sorichter S. Breath-hold diving. Med Sci Sports Exerc 2011;43(7):1214-1219.

8. Buscher H, Valta P, Boie T, Hinz J, Moerer O, Sydow M, et al. Assessment of diaphragmatic function with cervical magnetic stimulation in critically ill patients. Anaesth Intensive Care 2005;33(4): 483-491.

9. Walterspacher S, Schlager D, Walker DJ, Müller-Quernheim J, Windisch W, Kabitz HJ. Respiratory muscle function in interstitial lung disease. Eur Respir J 2013;42(1):211-219.

10. Lukácsovits J, Carlucci A, Hill N, Ceriana P, Pisani L, Schreiber A, et al. Physiological changes during low- and high-intensity noninvasive ventilation. Eur Respir J 2011;39(4):869-875.

11. Talmor D, Sarge T, Malhotra A, O'Donnell CR, Ritz R, Lisbon A, et al. Mechanical ventilation guided by esophageal pressure in acute lung injury. N Engl J Med 2008;359(20):2095-2104.

12. Loring SH, O'Donnell CR, Behazin N, Malhotra A, Sarge T, Ritz R, et al. Esophageal pressures in acute lung injury: do they represent artifact or useful information about transpulmonary pressure, chest wall mechanics, and lung stress? J Appl Physiol 2010;108(3):515522.

13. Petit JM, Milic-Emili G. Measurement of endoesophageal pressure. J Appl Physiol 1958;13(3):481-485.

14. Gibson GJ, Pride NB. Lung distensibility. The static pressurevolume curve of the lungs and its use in clinical assessment. Br J Dis Chest 1976;70(3):143-184. 


\section{Assessing Respiratory Function Depends on Balloon Catheter Characteristics}

15. Panizza JA, Finucane KE. Comparison of balloon and transducer catheters for estimating lung elasticity. J Appl Physiol 1992;72(1): 231-235.

16. Buscher H, Valta P, Sydow M, Thies K, Burchardi H. Pressure signal transmission of five commercially available oesophageal balloon catheters. Intensive Care Med 2000;26(4):462-465.

17. American Thoracic Society/European Respiratory Society. ATS/ERS statement on respiratory muscle testing. Am J Respir Crit Care Med 2002;166(4):518-624.
18. Milic-Emili J, Mead J, Turner JM, Glauser EM. Improved technique for estimating pleural pressure from esophageal balloons. J Appl Physiol 1964;19(2):207-211.

19. Technical Committee ISO/TC 121. Breathing machines for medical use-lung ventilators (ISO 5369). Geneva, Switzerland: International Organization for Standardization; 1987.

20. Milic-Emili G, Petit JM. Relationship between endoesophageal and intrathoracic pressure variations in dog. J Appl Physiol 1959;14(4):535-537.

This article is approved for Continuing Respiratory Care Education credit. For information and to obtain your CRCE

(free to AARC members) visit

www.rcjournal.com 